\title{
Da repressão à prevenção da violência: desafio para a sociedade civil e para o setor saúde
}

\author{
From repression to prevention against violence: \\ a challenge posed to civil society and the health sector
}

Alberto Concha-Eastman ${ }^{1}$
Miguel Malo ${ }^{1}$

\footnotetext{
${ }^{1}$ Pan American Health Organization, World Health Organization. 525 23rd St. N.W. Washington, D.C. 20037, USA. conchaal@paho.org
}

\begin{abstract}
This article deals with the proposal of the Pan American Health Organization for the prevention against violence, following the precepts of the World Report on Violence and Health of the WHO. In this analysis the authors distinguish the approach of public safety (generally based on repression) from the way public health approaches this issue, based on the traditional concepts that constitute its patrimony: promotion of health, prevention against lesions and physical and emotional injury, and the strengthening of citizenship. The authors show that the health sector has already embraced the issue definitively but that even so the problem is still far from occupying the outstanding place it deserves in the public health agenda, together with other health problems of the contemporaneous populations. The text concludes with establishing a link between prevention against violence and the millennium development goals, which in principle urge society for taking action towards human rights, solidarity and quality of life.
\end{abstract}

Key words Violence and health, Prevention against violence, Citizenship and violence
Resumo Este artigo trata da proposta da Organização Pan-Americana de Saúde (Opas) para a prevenção da violência, seguindo as orientações do Informe Mundial sobre Violência e Saúde da Organização Mundial de Saúde (OMS). Por meio dessa reflexão, os autores diferenciam a abordagem da segurança pública (geralmente fundamentada na repressão) do foco com que a Saúde Pública trata do tema, com os tradicionais conceitos que constituem seu patrimônio: promoção da saúde, prevenção de lesões e de traumas físicos e emocionais, e fortalecimento da cidadania. Os autores mostram que o setor saúde já vem definitivamente assumindo o tema, mas falta ainda muito para que adquira um lugar de destaque como outros agravos à saúde da população contemporânea. O texto termina articulando a prevenção da violência com as metas do milênio que, em última instância, concitam a sociedade para os direitos humanos, a solidariedade e a qualidade de vida.

Palavras-chave Violência e saúde, Prevenção da violência, Cidadania e violência 


\section{Um caminho ainda a percorrer}

Em 2002, a Organização Mundial da Saúde (OMS) publicou o Relatório Mundial sobre Violência e Saúde (RMVS) 1 , que resume tema discutido há décadas sobre a necessidade de mudar o paradigma da repressão e punição como única forma de se enfrentar a violência, optando-se pela prevenção com base em evidências. Tal relatório ofereceu um incentivo crucial em vários países das Américas e outras regiões do mundo para o estabelecimento de visão e propostas preventivas como questões primordiais nas agendas governamentais, já que representavam exigências constantes por parte das comunidades vítimas do problema. Ao invés de ser um produto instintivo, o RMVS resultou de muitos anos de trabalho, pesquisa, debates e controvérsias em diversos níveis e de pontos de vista de diferentes campos e instituições.

Nas Américas, já em 1993, o Conselho Diretor (CD) da Organização Pan-Americana de Saúde (Opas) aprovara uma Resolução que [...] insta os governos a estabelecerem politicas e planos nacionais [...] para prevenir e controlar a violência, com ênfase especial em grupos mais vulneráveis [...] A resolução, portanto, advogava um diferencial nas políticas repressivas e solicitava uma definição, mais precisa e baseada em estudos e dados confiáveis, de prioridades e grupos humanos sujeitos a maior risco de violência. Mais tarde, em 1994, dentro do escopo da "Conferência Interamericana sobre Sociedade, Violência e Saúde", pela primeira vez a OMS propôs um "Plano de Ação Regional sobre Violência e Saúde"2, que foi considerado um esforço pioneiro de uma organização internacional de saúde para introduzir a prevenção contra atos de violência na agenda pública, como advertência clara à necessidade de se desenvolverem obras multissetoriais. As estratégias e os objetivos definidos nesse plano visavam a preencher lacunas de prioridade, como a ausência de políticas públicas para enfrentar a violência, a falta de informações confiáveis, a necessidade de se promoverem pesquisas e de se conseguir maior participação dos cidadãos na busca de soluções para o problema.

Conseqüentemente, em 1996, o 39 CD da OMS aprovou a Resolução CD 39/14, na qual enfatiza que "a violência, em todas as suas manifestações, é uma prioridade da saúde pública", ao tempo em que solicita ao Diretor seja oferecida cooperação técnica para o fortalecimento dos governos dos paísesmembros no desenvolvimento de vigilância da violência epidemiológica, promoção de pesquisas, disseminação de informações e fomento da cooperação entre os países. Afinal, em 2003, o CD aprovou o documento "Repercussão da violência na saúde das populações americanas" e a Resolução CD $133 / 22$, que insta os governos a darem prioridade e apoio ao desenvolvimento de planos, programas e projetos em nível nacional e municipal na prevenção à violência de natureza social e relacionadas a sexo, etnia ou classe social" e a "aplicarem as recomendações estabelecidas no Relatório Mundial sobre Violência e Saúde 3 .

Entre outros méritos, o RMSV reuniu contribuições conceituais e propostas de intervenção em um documento de natureza global, juntamente com elementos de referência a políticas públicas na prevenção à violência. O RMSV adota enfoque baseado em ecologia como proposta teórica válida para abordar a questão da violência, em sua vasta complexidade, de modo que na elaboração das políticas e intervenções relacionadas à violência sejam levados em consideração tanto o planejamento quanto as medidas de natureza multissetorial, assim como o reconhecimento de uma abordagem integral que abranja das políticas públicas individuais às de caráter macro.

Além disso, o RMSV consegue articular a estrutura teórico-conceitual e as definições operacionais consensuais que contribuem para a formulação das propostas. Começa com a definição geral de violência como o uso intencional de força física ou poder, seja real ou por meio de ameaças, contra a própria pessoa, terceiros, grupo ou comunidade, que talvez ou muito possivelmente resulte em morte, lesão, dano psicológico, problemas de desenvolvimento ou privação (Capítulo 1), em que são proeminentes os componentes de intenção e dano e o uso do poder para praticar o ato de violência. Também aborda as manifestações específicas de violência, como a juvenil (Capítulo 2), o abuso ou maltrato de crianças (Capítulo 3); a violência doméstica (Capítulo 4) e a sexual (Capítulo 6); a violência a adultos (Capítulo 5), a auto-infringida (Capítulo 7) e a coletiva (Capítulo 8), para encerrar a discussão acerca das nove recomendações de aplicação nacional ou no contexto internacional.

A violência é classificada em três níveis, segundo sua expressão e natureza (física, sexual, psicológica ou decorrente de negligência) e, em geral, manifesta-se numa combinação: 1) interpessoal, que compreende a) violência intrafamiliar, pelo cônjuge, e cujas vítimas são mulheres, crianças e adultos, e b) pela comunidade, nas ruas e em locais públicos, que é cometida contra indivíduos conhecidos ou, às vezes, desconhecidos; 2) coletiva, por Estados, grupos organizados, crime organizado, podendo também ser social, econômica ou política; e, finalmente, 
3) auto-infringida, como o suicídio ou a tentativa de suicídio e outros tipos de auto-agressão.

Desde que o RMVS foi lançado perante as autoridades nacionais de quase todos os países das Américas, entre os quais Costa Rica, Nicarágua, Colômbia, Brasil, Honduras, Peru, México, Equador, Porto Rico, Panamá, El Salvador, Jamaica, Estados Unidos e Canadá, bem como em diversos eventos de nível municipal, é possível afirmar que as organizações internacionais, os ministérios da saúde e outras instituições governamentais e da sociedade civil reconheceram a violência como uma questão social e de saúde pública de abordagem multissetorial.

Em diversos países das Américas e outras regiões pelo mundo afora há avanços no sentido de se dar posição de destaque, nas agendas governamentais, à visão e às propostas preventivas, já que constituem exigência constante das comunidades vítimas da violência.

No entanto, os passos dados à frente não foram suficientes nem os únicos a tratar da questão da violência com a severidade e a urgência necessárias. $\mathrm{O}$ caminho a ser percorrido ainda é longo. A aliança global contra a violência promovida pela OMS (http://www.who.int/violenceprevention/em/index .html), à qual se podem associar instituições governamentais e não-governamentais e organizações internacionais, representa uma das oportunidades de se percorrer esse caminho.

\section{Envolvimento do setor de saúde na prevenção à violência}

Para a OMS a saúde pública constitui medida coletiva do Estado e da sociedade civil, visando a proteger e melhorar a saúde dos indivíduos. Trata-se de prática social de natureza multidisciplinar ${ }^{4}$, capaz de enfatizar que a responsabilidade do setor de saúde não se limita a recuperar indivíduos doentes ou vítimas de traumatismos; pelo contrário, deve buscar o bem-estar da população como condição vital para o desenvolvimento pessoal e coletivo. Por conseguinte, entendemos que questões sociais como a violência ou a falta de segurança nas ruas são questões de saúde pública. Além do impacto na saúde física, psicológica ou sexual de suas vítimas, a violência social e interpessoal tem efeitos sociais e afeta o desenvolvimento.

Em cidades ou países em que a violência e a sensação de insegurança do cidadão são altas, as populações têm sua vida cotidiana e mobilidade afetadas. Desse modo, a qualidade de vida é reduzida, gerando medos, quer baseados em motivos sólidos, quer não; a mobilidade livre e segura fica inibida; o espaço e o tempo, "restritos"; o espaço privado, confinado a quatro paredes; o público tende a desaparecer, afetando a saúde, já que limita os locais seguros nos quais as pessoas podem praticar atividades físicas e desportivas. As cidades gradualmente perdem os espaços públicos e cívicos, generalizando-se assim a urbanização confinada ao privado, que segrega ainda mais a social, espacial e temporal. Tudo isso corrói a cidadania da população, reduzindo seu caráter comunitário ${ }^{5}$.

No que diz respeito à violência contra as mulheres, cometida por seus parceiros, elas são afetadas no desenvolvimento pessoal e intelectual. A violência intrafamiliar destrói o espaço que sempre foi considerado o mais seguro da sociedade, pois constituído de membros ligados entre si por amor, respeito e proteção.

No tocante ao aspecto econômico, a violência e a insegurança do cidadão reduzem a possibilidade de investimento interno ou externo, com efeitos negativos na lucratividade social. Isso conduz a uma "economia" de violência e crime que pode ser avaliada pelo equilíbrio entre custos, riscos e benefícios. Nesse sentido, a possibilidade de prisão e punição (que se denomina impunidade quando há omissão do sistema) é menor, tendendo a um maior cometimento de crimes e atos de violência ${ }^{6}$. Certamente quanto mais fraco o Estado, mais altas são as possibilidades do aumento da atividade criminal. Em termos da estrutura social, a violência produz e gera danos porque fomenta comportamentos e atitudes que aniquilam os fundamentos e princípios da vida em sociedade e da solução de conflitos, destruindo, pois, o capital social. E, por fim, como Cruz enfatiza, ela afeta a governabilidade e enfraquece a democracia, em especial nos países com história recente marcada por conflitos sociais e políticos, onde a violência social aumentou? ${ }^{7}$.

Em síntese, a violência é uma questão de saúde pública porque:

1. Produz altas taxas de mortalidade e morbidez que atingem principalmente crianças, mulheres e jovens, situação que se agrava nos locais em que se registram altos níveis de violência, seja ela interpessoal ou coletiva.

2. Exige grandes montantes de recursos financeiros na prestação da assistência médica às vítimas, geralmente em detrimento da que deveria ser proporcionada a outros pacientes.

3. Afeta não só a vítima, mas a sua família e o ambiente circundante, produzindo efeitos negativos imediatos nos aspectos econômicos, sociais e psicológicos, também com impactos a médio e longo prazos. 
4. Afeta, ainda, o indivíduo responsável pelo ato de violência, sua família e a sociedade, já que, afora as despesas com a polícia, justiça e prisão (se aplicável), nessas circunstâncias o indivíduo não tem condições de contribuir para o desenvolvimento social e econômico da família, da comunidade e do país.

5. Afeta negativamente o desenvolvimento social e econômico das comunidades e dos países.

6. Afeta a vida cotidiana, a liberdade de locomoção e o direito de usufruir dos bens públicos.

Os progressos obtidos na saúde pública no que tange ao controle e à prevenção de doenças e à promoção da saúde também são válidos $\mathrm{e}$ pertinentes para enfrentar o problema da violência e as lesões sem dolo. As medidas preventivas e as orientadas para promover a saúde tentam impedir a ocorrência desses atos e o agravamento de suas conseqüências, ao tempo em que favorecem condições capazes de coibir a reprodução de (situações de) riscos que levam a tais fatos. O enfoque em estudos e pesquisas voltados para a solução da violência baseia-se em provas científicas, historicamente empregadas para resolver questões de saúde pública. Desse modo, sugerem-se os seguintes passos com o intuito de se passar do problema para a solução $0^{8,9,10}$.

- Tomar ciência de manifestações da violência por meio da coleta de dados sistemáticos (vigilância epidemiológica ou informações para tomada de decisão) sobre sua magnitude, escopo, características e conseqüências em nível municipal (local) ou nacional. Isso não só permite o estabelecimento da magnitude do problema, em termos quantitativos, como possibilita a identificação de possíveis associações e causalidades que devam ser exploradas em maior profundidade. Ao mesmo tempo, enseja o conhecimento do tipo de violência que afeta, em maior ou menor grau, determinada comunidade, seja ela contra mulheres e crianças, sexual, juvenil, auto-infringida ou coletiva.

- Pesquisar, com maior rigor científico, as causas e/ou vínculos causais, que comprovem:

1) aspectos contextuais que determinam a reprodução social das condições de risco;

2) causas e/ou fatores que aumentam ou reduzem o risco da ocorrência de atos de violência;

3) comportamentos, atitudes e crenças passíveis de mudanças por meio de intervenções multissetoriais e/ou de saúde.

- Elaborar estratégias e intervenções com vistas a impedir a violência, empregando as informações descritas acima, para permitir a execução, supervisão e avaliação das intervenções, além de desenvolver, em diversas circunstâncias, intervenções - testadas ou promissoras - seguidas de ampla disseminação de informações e do estabelecimento de programas de eficiência de custos.

- Fomentar medidas multissetoriais para estabelecer a necessária articulação entre diversos setores da gestão governamental, cujo envolvimento seja imprescindível ao desenvolvimento de uma abordagem integral da violência, além da promover a permanente participação da sociedade civil.

- Avaliar os resultados e reformulá-los sempre que for conveniente.

Assim sendo, o setor de saúde se sente compelido a assumir a responsabilidade no que se refere à abordagem da questão da violência, começando pela devida assistência às vítimas, passando pela geração de informações de qualidade e, finalmente, chegando à liderança, facilitação e participação conjunta com outros setores para definir e executar políticas públicas integrais na prevenção à violência e na promoção da saúde.

\section{Metas de Desenvolvimento do Milênio (MDM) e a prevenção da violência}

Muito embora nem as MDM nem os indicadores para monitorar seu progresso façam expressa referência à violência, pode-se facilmente encontrar um elo entre as $8 \mathrm{MDM}$ e a violência, havendo, portanto, à luz de sua prevenção, uma contribuição no sentido de se alcançarem as metas. Adiante apresentamos breves comentários a respeito de cada uma das MDM e suas implicações sobre a violência contra mulheres ${ }^{11,12}$, crianças e jovens.

\section{MDM 1. Erradicar a pobreza extrema e a fome}

A prova da ligação entre pobreza e violência não é cabal, isto é, ainda não foi comprovada e, desse modo, não se pode aceitar ou afirmar que os pobres, por essa sua condição, sejam mais violentos do que os possuidores de recursos econômicos. Sabe-se que os pobres são mais vulneráveis devido à falta de espaços de lazer, ao nível educacional mais baixo e a outras privações sociais e ambientais. A fome e a necessidade de prover alimentos à família levam muitos, em desespero, a furtar e, às vezes, a cometer delitos mais graves.

Também se sabe que a desigualdade social, medida pelo Índice de Gini ou outros indicadores, está associada à violência. $\mathrm{O}$ aumento de $1 \%$ no coeficiente de Gini está associado ao aumento de 1,5\% nas taxas de homicídio e ao au- 
mento de 2,6\% nas de furtos. No caso de agravamento constante no desequilíbrio da receita, os efeitos permanentes são 3,7 e 4,3 vezes mais altos nos homicídios e furtos, respectivamente. Por outro lado, à luz do desenvolvimento, o aumento de $1 \%$ no PIB leva à redução de $2,4 \%$ nas taxas de homicídios e de $13,7 \%$ nas de furtos ${ }^{13}$. Um estudo desenvolvido pelo Banco Interamericano de Desenvolvimento (1997) na América Latina estimou que os custos sociais acarretados pelo crime, inclusive o valor dos bens furtados, são equivalentes a 163 bilhões de dólares dos EUA, ou 14,2\% do PIB da região ${ }^{14}$. A desigualdade e a pobreza constituem fatores de risco, aumento da vulnerabilidade da violência nos lares e nos ambientes sociais. A violência doméstica está associada (também ela foi medida) a famílias e lares que enfrentam a pobreza; contudo, uma vez mais, não se pode afirmar a existência de um vínculo direto entre pobreza e violência. Havendo aumento dos recursos familiares, a expectativa é de que haja melhora nos índices de violência (embora isso deva estar associado a outras MDM).

- A participação feminina na economia e sua independência econômica conferem às mulheres autonomia para evitar a violência por parte de parceiro ou cônjuge e, por conseguinte, seria necessário elevar o número delas com acesso a fontes de receita, independentes do parceiro ou cônjuge.

- Evitar que crianças, adolescentes ou jovens assistam a atos de violência em casa, contribuindo, assim, para impedir a repetição de comportamentos violentos em suas vidas futuras.

MDM 2. Atingir o ensino primário universal

A instrução abre portas para empregos e para o conhecimento. A falta de instrução favorece as agressões; graças à ignorância, muitas pessoas nem conhecem seus direitos. Diversos estudos realizados pelo Unicef e pela OMS revelaram amplamente os efeitos positivos da instrução das mães no que se refere à saúde dos filhos.

- A instrução das mulheres melhora sua auto-estima, socialização e participação em redes sociais, aumenta a possibilidade de conhecerem seus direitos e ajuda a reduzir a desigualdade. As mulheres sem instrução sofrem violência e não procuram ajuda. A participação feminina nas redes sociais é um fator comprovado de proteção contra a violência, reduzindo assim o risco de sua repetição.

- Crianças e jovens sem instrução apresentam maior tendência à violência e ao consumo de drogas.

- O acompanhamento das atividades escolares e extracurriculares das crianças pelos pais e mães reforça os vínculos familiares, favorece a socialização a partir do lar e reduz o risco de violência e/ou agressão nas ruas.

MDM 3. Promover a igualdade entre os sexos e a autonomia das mulheres

A igualdade dos sexos é reconhecidamente um fator predominante na luta contra a violência entre os sexos e as agressões sexuais, físicas e psicológicas contra a mulher.

- Quanto maior a desigualdade entre os sexos, maior a violência e os abusos praticados pelos cônjuges contra a mulher. A conquista da igualdade entre os sexos não só confere autonomia à mulher como está diretamente relacionada à redução da violência contra ela.

- Aprender sobre a igualdade entre os sexos desde a infância, adolescência e juventude constitui outro elemento de proteção contra a violência e de reforço à igualdade. Jovens e adultos do sexo masculino com senso de igualdade não agridem nem maltratam suas parceiras.

\section{MDM 4. Reduzir a mortalidade infantil}

A morte prematura de crianças (não como ocorrência individual, mas populacional) é conseqüência de desequilíbrio social, falta de acesso aos serviços de saúde, estando associada à falta de instrução e à baixa autonomia das mães. Portanto, reduzir a mortalidade infantil é um fator de desenvolvimento que contribui para abrandar os desequilíbrios e gerar maior segurança.

- Alguns casos de mortalidade infantil estão relacionados à violência contra as mães.

- Quanto mais alta a mortalidade infantil, maior a natalidade, o que contribui para a perpetuação do ciclo de desigualdade e pobreza.

\section{MDM 5. Melhorar a saúde materna}

Conforme mencionado acima, atingir outras $\operatorname{MDM}(1,2,3)$ em que as mulheres desempenham papel primordial é vital para alcançar o desenvolvimento em termos nacionais. A questão das mulheres grávidas e do parto iminente é particularmente sensível. A melhoria da assistência e dos direitos das mulheres grávidas contribui bastante para a redução da violência durante a gravidez e após o parto.

- Há provas documentais de que a violência contra as mulheres grávidas cometida pelo cônjuge afeta a saúde tanto da mãe quanto do feto. A violência con- 
tra a mulher grávida é inaceitável. Alguns estudos revelaram retardo no desenvolvimento fetal intrauterino devido à violência doméstica. Outros estudos sugerem que as mulheres sujeitas a abusos são passíveis de partos prematuros. Há estudos sobre a relação entre a morte de fetos ou recém-nascidos e as agressões contra a mãe e, conquanto ainda não sejam conclusivos, outras ligações possíveis sugerem que devam ser mais bem explorados. Alguns estudos revelam taxa de hospitalização mais elevada entre mulheres submetidas a abusos, bem como maior possibilidade de partos por cesariana.

- As crianças e os jovens que assistem a violências contra a mãe, principalmente se ela estiver grávida, desenvolvem problemas e correm o risco de se tornar violentas mais tarde. As crianças de mães espancadas estão sujeitas a maior risco de virem a sofrer abusos.

\section{MDM 6. Combater HIV/Aids, malária e outras doenças}

A alta incidência e prevalência de HIV e Aids é um fator de instabilidade social e familiar. Os estupros constituem fator de alto risco de contaminação do vírus por mulheres e crianças.

- A alta incidência de infecção por HIV e Aids entre mulheres coloca os lares em risco, sendo motivo e conseqüência de violência, abandono e exclusão pelos parceiros.

- Muitas mulheres não exigem que os parceiros usem preservativos ou se submetam a teste de HIV por medo de eles praticarem atos violentos.

- A prostituição infantil e juvenil (de ambos os sexos) é uma espécie de violência com alto risco de HIV e Aids.

\section{MDM 7. Garantir a sustentabilidade ambiental}

Os conflitos violentos, principalmente as guerras, os conflitos internos denominados de média ou baixa intensidade, a ação de grupos organizados como guerrilheiros, paramilitares e, hoje em dia, traficantes de drogas, trazem danos ao ambiente, geram pobreza e fome entre as pessoas deslocadas, favorecem os estupros e abusos contra menores. A vinculação entre conflito e meio ambiente dever ser observada para se evitar e/ou impedir mais danos e, provavelmente, maior violência.

- Em conflitos violentos coletivos, as mulheres, principalmente as que estão sozinhas, sofrem risco mais alto de abusos por parte dos integrantes das forças em conflito. Por outro lado, elas podem ser fator de recuperação e/ou manutenção de zonas específicas.

- As organizações fora da lei usam menores em suas ações, tanto no campo quanto na cidade, muitas das quais com efeitos ambientais negativos. O Estado e as famílias podem desempenhar papel especial no sentido de evitar que crianças e jovens sejam usados para fins criminosos com danos ambientais.

\section{MDM 8. Estabelecer uma parceria global para o desenvolvimento}

Indubitavelmente, os esforços mundiais conjuntos para o desenvolvimento deverão influenciar todas as MDM e, desse modo, trarão efeitos positivos para a prevenção e o controle da violência.

- É válido reafirmar que o equilíbrio entre os sexos, a autonomia, a instrução e o emprego das mulheres são passos firmes em direção ao desenvolvimento e, portanto, fatores decisivos para reduzir a violência contra as mulheres.

- Ambientes e famílias saudáveis, onde jovens e crianças podem se desenvolver, freqüentar a escola, não passar fome e usufruir dos direitos sociais, possibilitarão a redução do risco de se tornarem vítimas e autores da violência.

A reflexão sobre as MDM e suas implicações na violência reforçam a necessidade de um enfoque preventivo, que vem sendo discutido e promovido há décadas. Muito embora não seja exaustiva, a discussão desse tema ajuda a identificar conexões que permitam medidas multissetoriais e interdisciplinares voltadas para a prevenção. Por exemplo, os projetos dirigidos ao fortalecimento das famílias terão impacto nas MDM e na prevenção à violência.

\section{Ênfase na prevenção}

A abordagem governamental histórica do controlerepressão transforma-se em prevenção, mas de maneira dinâmica e interativa. A evolução de como enfrentar a questão da violência caracteriza-se por três momentos:

\section{Momento 1: repressão e controle}

Sob a responsabilidade da polícia e do sistema judiciário. As teorias fundam essa medida no efeito intimidativo sobre os potenciais agressores por meio da prisão e perda de direitos empregados pelo Estado para punir os que infringem a lei. Tal política não alcançou a eficiência esperada ${ }^{15}$. Essa abordagem costumava ser a tradicional e, conquanto isolada, não produz os efeitos esperados. Ademais, seria necessário manter-se em mente que os autores de crimes ou atos de violência devem estar sujeitos a leis que, quando justas, equilibradas e 
respeitadoras dos direitos humanos, precisam ser aplicadas agora e sempre.

\section{Momento 2: multicausalidade e prevenção}

No decorrer das três últimas décadas, houve um aumento da necessidade de abordar a violência por uma perspectiva preventiva ampla. Tratase de uma reação multissetorial para a multicausalidade da violência. Agora, reconhece-se e se aceita o fato de que diferentes setores relacionados à atenção, à reabilitação, ao cuidado e ao controle das vítimas e dos perpetradores de atos violentos devem unir esforços no sentido de impedir a violência. Segundo essa visão, as medidas multissetoriais tentam defrontar a multicausalidade, atuando de maneira preventiva e integrada de modo a enfrentar o crime e, ao mesmo tempo, tentar construir a cidadania. Os programas ou as intervenções de cunho preventivo devem ser integrais e reativos em duas dimensões.

1) Dimensão temporal. É primária quando a ação se desenvolve antes do acontecimento; na família, por meio da chamada escola de pais, com ambientes não violentos e disciplina positiva e orientadora; na escola, melhorando a instrução e reforçando a solidariedade; na comunidade, respeitando as normas e adotando uma cultura de vida social e de cidadania; no Estado, mostrando o exemplo dos líderes e gerindo corretamente os negócios públicos. A prevenção é essencial na missão da Opas, em especial na prevenção primária. Ela tem como objetivo fomentar um ambiente social e individual de respeito e tolerância, valores sociais e comportamento pessoal que favoreçam a solução não violenta de conflitos, isto é, voltados para evitar o fato violento. Fazem parte desse nível de prevenção, por exemplo, as macroestratégias direcionadas à redução da pobreza, buscando equilíbrio social e melhoria da educação, ou recuperação da ética e do controle social.

Emprega-se a prevenção secundária quando o ato de violência já ocorreu e a intenção é evitar episódios novos ou mais graves. Para a violência contra as mulheres e em caráter individual, os grupos de assistência às vítimas produzem efeitos positivos. Para a prevenção secundária funcionar de maneira apropriada no setor de saúde, seria necessário mudar a atitude dos profissionais do setor de modo a qualificá-los a detectar casos e a utilizar os programas de encaminhamento e vigilância epidemiológica, ao invés de se limitarem apenas ao atendimento necessário. Entre os exemplos desse tipo de prevenção secundária, há programas que identificam os que recorreram a instituições de saúde por terem sofrido lesão grave e são, então, encaminhados a programas de intervenção em situações de crise, que exigem a solução das situações que precederam o ato de violência ${ }^{16}$. Os Serviços de Aconselhamento para mulheres e crianças, que proporcionam apoio e atendimento na solução da violência intrafamiliar, e as Visitas Domiciliares de terapeutas às vítimas da violência também são medidas de prevenção secundária17-20. As redes locais e os grupos que atuam na prevenção da violência, além das medidas que aumentem a capacitação do pessoal de saúde, são alternativas de prevenção em diversos países ${ }^{21,22}$. A prevenção secundária também é direcionada a agressores do sexo masculino e feminino. Os grupos do sexo masculino e as "Escolas de Pais" objetivam mudar os comportamentos agressivos nos relacionamentos intrafamiliares e entre os cônjuges. Outro caso é o dos programas para jovens envolvidos em gangues, nos quais eles analisam e buscam diferentes opções de vida. Exemplos desse tipo de programa são os denominados Programa Polígono Industrial e Homies Unidos ${ }^{23}$ em São Salvador.

Emprega-se a prevenção terciária na saúde pública para evitar maiores danos aos doentes, melhorando sua qualidade de vida. Objetiva a reabilitação. No que tange à violência, ela é aplicada aos condenados que estão cumprindo pena. Os programas de prevenção terciária devem focalizar atividades produtivas de ensino, oferecer assistência psicológica e ressocialização. A prevenção terciária é particularmente importante para os jovens detidos por infrações de menor gravidade. Com freqüência, devido à falta de reabilitação, o período do cumprimento da pena serve para intensificar a atividade criminal desses jovens.

2) A segunda dimensão é a do indivíduo ou do grupo de cor branca $E$ universal quando voltada para a comunidade ou a sociedade em geral, como, por exemplo, controlar o consumo de álcool ou promover a cultura da cidadania. É seletiva quando aplicada a grupos de risco, como, por exemplo, as Visitas Domiciliares que devem ser marcadas desde a gravidez e reforçadas com a família durante a primeira infância da criança. Finalmente, pode ser indicada para grupos ou indivíduos com alto risco de sofrer violência, como mulheres, crianças vítimas de abuso e jovens integrantes de gangues.

Momento 3: Recuperação dos vínculos sociais e humanos

A violência, principalmente em grande escala, produz e gera danos à estrutura social, fomenta 
comportamentos que corroem os fundamentos e os princípios da vida social e da solução de conflitos. Isso é mais observável nos países em que os níveis de violência são altos, com expressões diárias e múltiplas. Aqui, o exemplo mais significativo e preocupante seria o tráfico de drogas, já que seu poder econômico permeia diversos níveis sociais e políticos, corrompendo o conceito de ética social, o respeito aos direitos de terceiros, o que Savater define como "a tentativa de melhorar os indivíduos"24 em seus relacionamentos com os outros. Sob esse enfoque, que vem se fortalecendo ao longo dos últimos dez anos, seria necessário intervir na prevenção à violência consoante um compromisso amplo dos cidadãos, líderes, comunicadores, educadores, finalmente, a sociedade como um todo, na luta pela recuperação da ética e do capital social.

\section{Considerações finais}

Os três momentos devem ser concomitantes, para se obter impacto positivo e holístico na solução do problema. Eles não são mutuamente excludentes. Quanto maior for a interação, melhores serão as chances de sucesso.

Independentemente do caso, da dimensão ou do nível de prevenção sujeito à intervenção, é necessário levar-se em conta que as propostas precisam ser analisadas com cautela, por se tratar de um campo social e de saúde pública com relativamente pouca experiência. Não existe receita ou modelo único. É necessário definir as intervenções com base em provas científicas analisadas sob critérios que permitam afirmar se elas produzem impacto, se são eficientes ou promissoras em termos de custo. As intervenções devem ser feitas mediante projetos examinados e baseados em princípios gerais claros, talvez experimentais, de efeito comprovado (importância estatística) e repetido em locais diferentes, com sustentabilidade e resultados a longo prazo.

Muitos projetos falham porque buscam impactos políticos de curto prazo (os governos são de curto prazo, ao contrário da recuperação da vida na sociedade), não recebem o devido financiamento, estão sob liderança fraca (perdem o efetivo compromisso por parte de autoridades ou gestores), estrutura teórica precária ou expectativas pouco realistas.

A prevenção à violência e à insegurança do cidadão deve ser desenvolvida em duas dimensões: a objetiva, relacionada a atos concretos de violência; e a subjetiva, ligada à percepção e à representação da violência pelos cidadãos. Essa última compreende, por exemplo, a imagem tida de uma cidade (cidade segura) ou de um bairro (bairro perigoso), a legitimidade das instituições e as avaliações ou percepções da população sobre si mesma.

Se no escopo da sociedade conseguirmos criar uma cultura de paz e respeito pela diferença de idéias ou crenças; se pudermos solucionar os conflitos sem fazer uso de agressão ou violência; se no nível social ou interpessoal tivermos êxito em impedir a ocorrência de homicídios, roubos, abusos sexuais, agressão no ambiente intrafamiliar, luta de gangues juvenis e, além disso, se no nível do Estado as guerras e os conflitos internos se tornarem histórias do passado, de modo a observarmos não somente uma redução significativa no número de pacientes vítimas da violência, estaremos vivendo em sociedades melhores, nas quais os esforços seriam voltados para a busca da igualdade, contribuindo para o desenvolvimento das pessoas. Para alcançar isso, é mister reconhecer que se trata de um desafio a longo prazo, tanto do setor de saúde quanto da sociedade civil como um todo.

\section{Colaboradores}

A Concha-Eastman e M Malo participaram igualmente de todas as etapas da elaboração do artigo. 


\section{Referências}

1. Krug EG, Dahlberg LL, Mercy JA, ZWI AB, Lozano R, editores. Informe mundial sobre la violencia y la salud. Washington, DC: OMS; 2002.

2. Organización Panamericana de la Salud. Plan de acción regional sobre violencia y salud. En: OPS/OMS, Sociedad, violencia y salud. Washington DC: OPS; 1995.

3. Pan American Health Organization. Directing Council Resolutions. Disponível em: http://www.paho.org.

4. Pan American Health Organization. La salud pública en la Américas. Nuevos conceptos, análisis del desempeño y bases para la acción. Publicación OPS, Científica y técnica No 589, Washington, DC 2002.

5. Carrión F. De la violencia urbana a la seguridad ciudadana Revista Pretextos. Lima: Ed. DESCO; 1996.

6. Ehrlich I. Crime, punishment and the market of offenses. J Economic Perspectives 1996; 10(1):43-67.

7. Cruz JM. Violencia y democratización en Centroamérica: el impacto del crimen organizado en la legitimidad de los regímenes de posguerra. América Latina Hoy 2003; 35:19-59.

8. Hammond R. The public health model for violence prevention: the CDC perspective. In: Violence and health. Proceedings of a WHO global symposium. Kobe, Japan, Oct. 1999. WHO Kobe Centre for Health Development. WHO, 2000.

9. Prothrow-Stith D. The Epidemic of Youth Violence in America: Using Public Health Prevention Strategies to Prevent Violence. J. Health Care Poor Undeserved 1995; 6(2):95-101.

10. McAlister A \& Velez LF. Behavioral sciences concepts in research on the prevention of violence. Rev Panam Salud Pública/Pan Am J Public Health 1999; 5(4/5):316-21.

11. World Health Organization. Addressing violence against women and achieving the Millennium Development Goals. Washington, DC: WHO; 2005.

12. Pallito CC. Domestic violence and maternal, infant, and reproductive health: a critical review of the literature, Washington, DC; 2004. [Mimeo].

13. Fajnzylber P, Lederman D, Loaiza N, editores. Crimen y violencia en América Latina. Bogotá: Banco Mundial-Editorial Alfaomega; 2001.

14. Londoño JL, Guerrero R. Violencia en América Latina: epidemiología y costos. Washington DC: Banco Interamericano de Desarrollo/Red de Centros de Investigación de la Oficina del Economista Jefe; 1999. (Documento de Trabajo R-375)
15. Instituto Regional de Asesoría en Derechos Humanos. Conferencia Regional sobre la Situación Carcelaria en la Región Andina. Quito: Ed. INREDH; 2000.

16. Concha-Eastman A, Espinosa R, Pineda ME, Melo LM, Becerra ML, Martínez LM, Machado A. Health sector assistance approach for victims of violence in a developing country. Apresentado no 10th International Symposium on Victimology, Montreal; 2000.

17. Olds DL, Henderson CR, Jr., Chamberlin R, Tatelbaum R. Preventing child abuse and neglect: a randomized trial of nurse home visitation. Pediatrics 1986; 78(1):65-78.

18. American Academy of Pediatrics. The role of home-visitation programs in improving health outcomes for children and families. Pediatrics 1998; 101(3):486-89.

19. Roberts I, Kramer MS \& Suissa S. Does home visiting prevent childhood injury? A systematic review of randomized controlled trials. BMJ 1996; 312:29-33.

20. Olds DL, Eckenrode J, Henderson CR, Kitzman H, Powers I, Cole $\mathrm{R}$ et al. Long-term effects of home visitation on maternal life course and child abuse and neglect. Fifteen-year follow-up of a randomized trial. JAMA 1997; 278(8):637-43.

21. Ellsberg M, Clavel-Arcas C, Montenegro T, Norori L, Quintanilla M. Cómo atender a las mujeres que viven situaciones de violencia doméstica? Orientaciones básicas para el personal de salud. Manágua: Editorial INPASA, Red de Mujeres contra la Violencia; 1998.

22. Zegarra TM. Redes locales frente a la violencia familiar. Lima: OPS; 1999.

23. Cruz JM, Portillo Peña N. Solidaridad y violencia en las pandillas del Gran San Salvador. Más allá de la vida loca. San Salvador: UCA Editores; 1998.

24. Savater F. Etica, política y ciudadanía. México: Editorial Grijalbo; 1998.

Artigo apresentado em 4/04/2006

Aprovado em 19/04/2006

Versão final apresentada em 19/04/2006 